ROAD SAFETY

\title{
In-vehicle communication systems: the safety aspect
}

\section{A Pauzié}

Injury Prevention 2002;8(Suppl IV):iv26-iv29

See end of article for author's affiliation

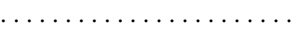

Correspondence to: Dr A Pauzié,

INRETS/LESCOT

Lyon-Bron, France; pauzie@inrets.fr
Communication and information technology are developing very rapidly at present. At the same time, the number of older drivers is increasing. When designing systems for elderly drivers, it has been shown that: (1) simplifying a task reduces performance differences between old and young; and (2) the optimization of onboard systems (better legibility and intelligibility of the information, simplified dialogue) in relation to the abilities of elderly drivers benefits the rest of the user population. Elderly people do not automatically reject new information and assistance technologies especially when the systems are user friendly. However, the ergonomics of these new technologies must be studied, with particular attention to the specific needs of the elderly, in order not to marginalize them
C ommunication and information technology are developing very rapidly at present, having a significant social impact, notably in transport, both in France and internationally. At the same time, the number of older drivers is increasing, due partly to demographics and partly to the habits of a generation which has seen a huge increase in car use over the last decades.

Ergonomic theory and practice will concern ways of integrating the elderly into this context of change. Considering people's right to and need for mobility, systems design must not only include the older generations, but also integrate information systems specifically adapted to them. Accident statistics for road safety show elderly drivers to be at risk, mainly for reasons connected with their functional abilities.

Apart from changes to the infrastructure, accompanied by training and information campaigns, new technologies in vehicles themselves can provide concrete and appropriate solutions. If such technologies make a positive contribution in terms of general road safety, the contribution is greater for a population with perceptive, cognitive, and motor deficiencies. In some cases, these systems can constitute electronic palliatives, provided that their design ergonomics are applied appropriately.

\section{FUNCTIONS OFFERED BY COMMUNICATION SYSTEMS}

Communication systems built into automobiles are aimed at increasing the occupant's comfort and safety. There are two separate categories: information systems offering help messages to the driver, who can decide whether to act on them or not; and assistance systems involved more or less independently with the actual control of the vehicle in emergencies or in clearly identified contexts.

\section{Information systems}

Guidance systems

Guidance information facilitates orientation by giving the driver, in real time, visual and aural help in reaching a predefined destination. Figures 1 and 2 show examples of two systems, one for guidance, the other for traffic information.

\section{Traffic information}

Critical situations can be avoided by the integration of real time traffic information. A guidance system can use this information in order to formulate the best route, taking into account the state of the roads at a given moment.

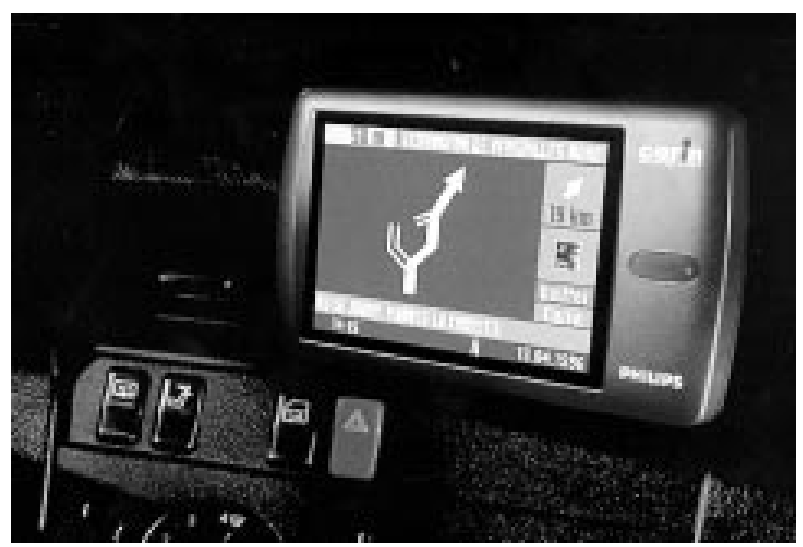

Figure 1 Guidance system.

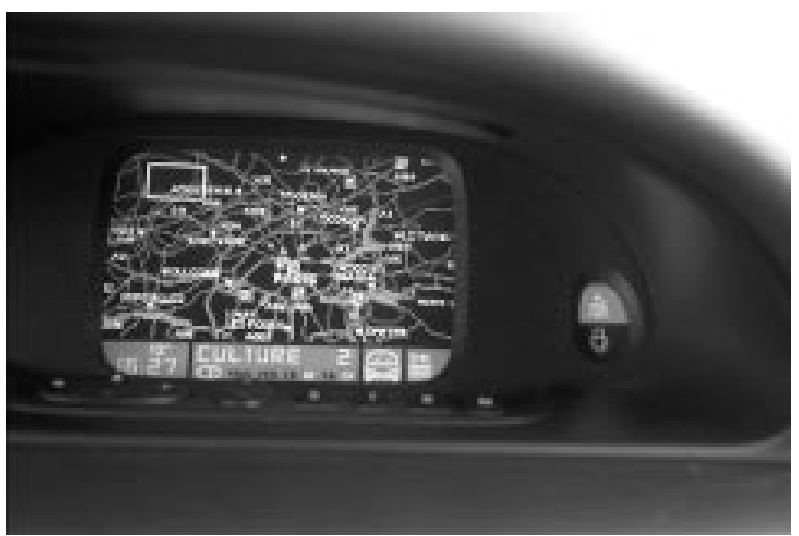

Figure 2 Traffic information system.

\section{Warning messages}

These warn drivers in good time about traffic situations or weather on the route to come, so that evasive action can be taken.

\section{Assistance systems}

In case of an accident or other emergency, automatic systems are engaged automatically. These systems can cover the slow reactions and indecision that can afflict anyone when driving, but especially older drivers. An example of one function would be obstacle detection. 


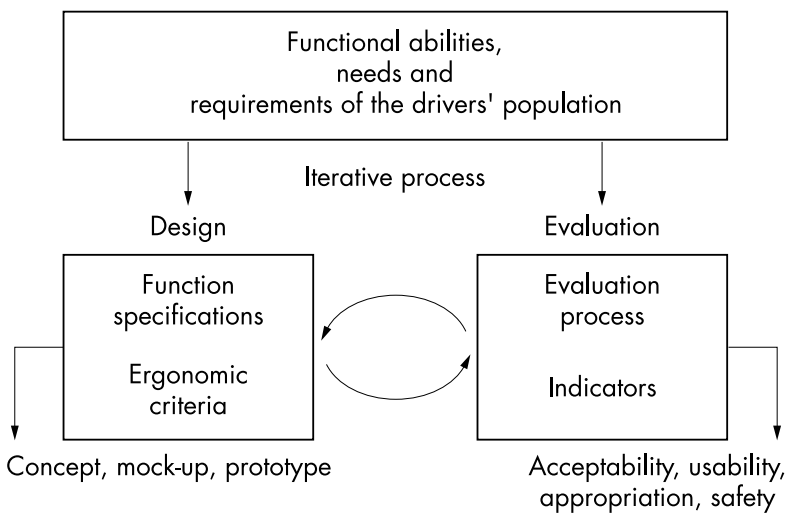

Figure 3 The involvement of ergonomics in the iterative design process and in transport systems evaluation.

\section{ERGONOMICS}

The aim of the ergonomists is to communicate data from their ongoing research to the various players in the transport field so that these information and assistance systems target drivers' safety and comfort, without excluding anyone. Ergonomic information is structured so that it can be used by the systems' designers and builders, notably by developing tools to help with design and evaluation. This ergonomic element must be incorporated into different steps of design, from the definition of technological concepts to the evaluation of operational systems via specifications during the iterative design process. Figure 3 shows the involvement of ergonomics in the iterative design process and in transport systems evaluation.

This ergonomic procedure is not only useful to the general population; it can also increase the competitiveness of the industry. It does this by getting manufacturers right from the early stages to think about equating the product with future users' needs, expectations, and abilities.

\section{Better understanding of the functional abilities of the elderly}

One fundamental element of the ergonomic procedure is to know users' functional abilities and needs, so that certain rules of design can be based on these data. The research involves laboratory experiments on a driving simulator, or experiments in real life situations.

Analysis of the perceptual cognitive processes in the laboratory

For the visuo-attentional aspects, a laboratory study has shown that the ability to detect eccentric targets varies according to the complexity of the central task (see fig 4); and that dividing attention between the main and peripheral tasks is considered by the aged to be harder as the complexity of the main task increases. ${ }^{1}$ The eccentricity of the target entails a

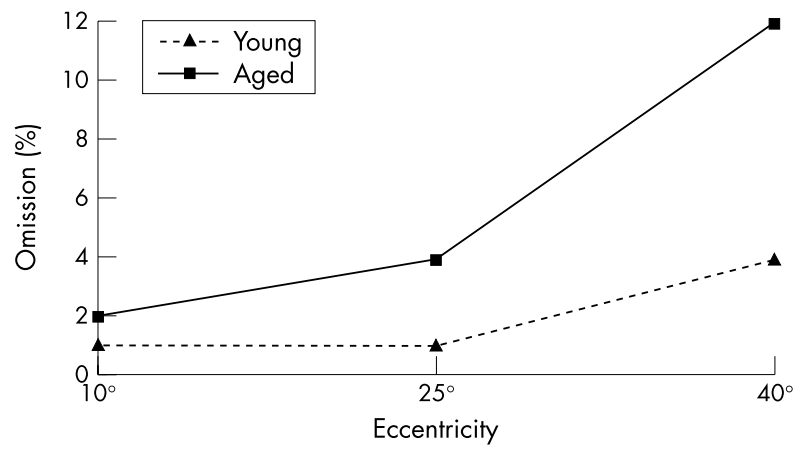

Figure 4 Omission errors in relation to the eccentricity of stimulus appearance.

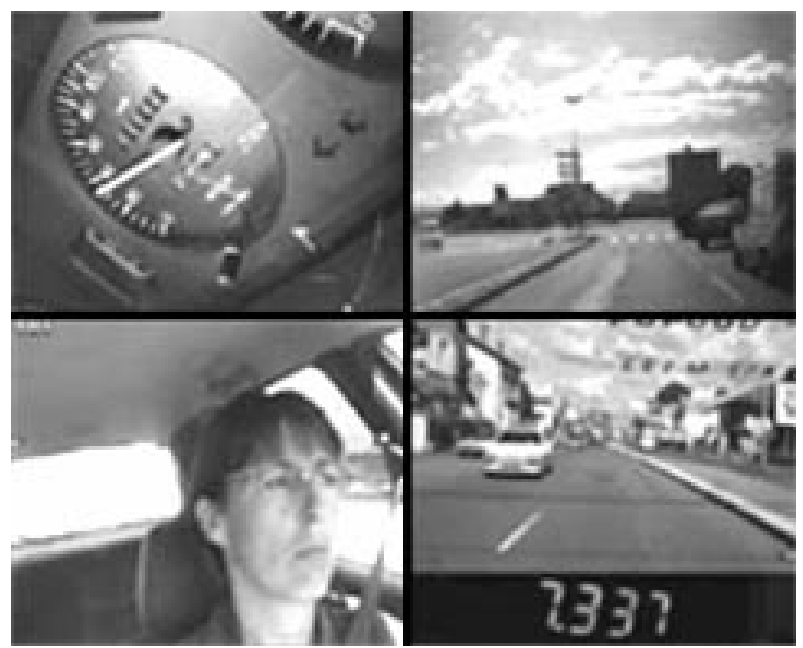

Figure 5 Quadravision shot (four miniature cameras set up in the experiment vehicle).

high non-detection rate in old people in comparison with young people. This disparity is more pronounced as the angle of eccentricity increases. This type of result is useful in the context of visual message display in the cab interior.

Analysis of behaviour in a real life situation

The preferred analysis is that of the driver in an actual driving situation, because it reveals so much. It allows for a relatively accurate and objective (as far as this is possible) quantification of the difficulties encountered by drivers on the road (number of mistakes, time taken to obtain information, spontaneous verbalizations, swerves, etc), and reveals how information is sought (analysis of visual strategies in terms of duration and frequency of glances at identified sources of information, number and type of actions to obtain information, etc) as well as effective performance in a given context (efficacy of the action, etc). The notion of visual strategy quantification is furthermore one of the criteria used by the group ISO TC22SC13WG8 mandated to establish a record of the normative workloads relative to the interface between the driver and the onboard system.

The tools used during these real life experiments, apart from some sensors on the vehicle, are essentially quadravision video (four miniature cameras taking different shots at the same time (see fig 5), the placement of the cameras depending on the context and the aim), sometimes accompanied by an audio recording.

Legibility of information displayed on-screen

One experiment explored the ability to read text information displayed on a screen mounted on the vehicle dashboard. A thorough analysis of the visual strategies used by drivers in a real driving situation was performed in terms of the frequency and duration of glances at the screen, for two possible character sizes $\left(23.8^{\circ}\right.$ angles, "small characters"; and $36.5^{\circ}$ angles, "large characters"), the words displayed having different lengths and different meanings. ${ }^{2}$

The analysis of glance frequency indicates a remarkable consistency, regardless of the character size and the age of the driver, even given that older drivers consult the screen slightly more often (non-significant trend) (see fig 6).

Glance duration reveals much about modes of operation and the difficulties encountered by elderly drivers: the small character size $\left(23.8^{\circ}\right)$ forces the person to look at the screen significantly longer in order to read the text. However, this age related difference disappears with the larger $\left(36.5^{\circ}\right)$ characters (see fig 7). 


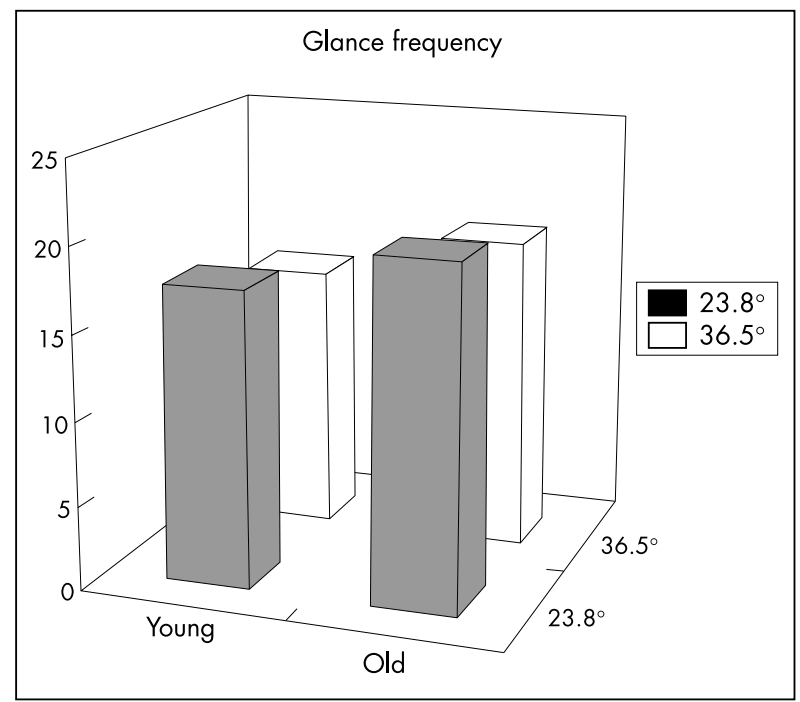

Figure 6 Average glance frequency according to driver age and character size. $^{2}$

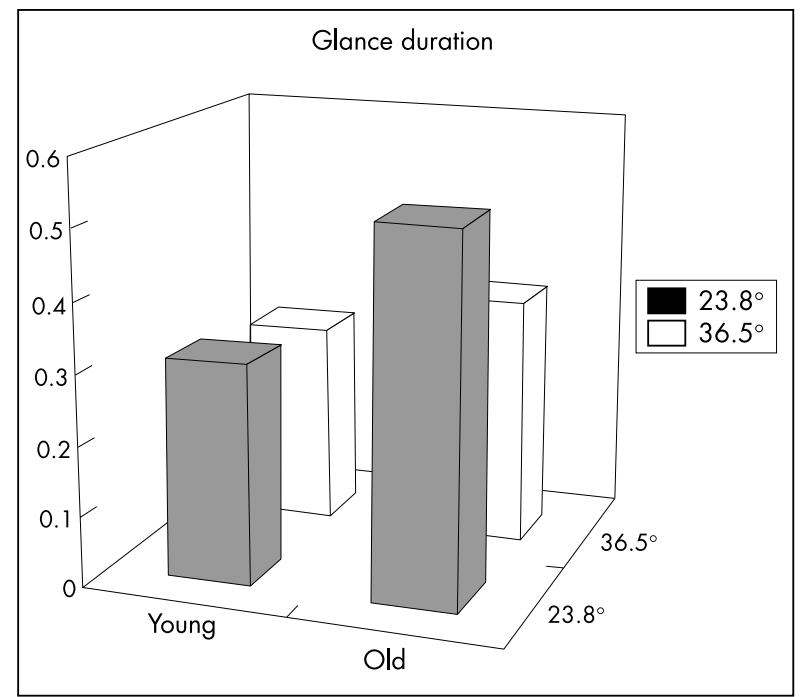

Figure 7 Average duration of glance according to driver age and character size. ${ }^{2}$

This result tells us that optimal legibility allows elderly people to perform similarly to young people, while in the harder situation (where the characters are smaller), they perform significantly worse.

\section{Ergonomics of guidance and navigation information}

Real life experiments on different guidance and navigation systems have shown how useful and efficient this type of assistance is for drivers, regardless of age. When the information is presented clearly, in the form of contrasting arrows displayed before each intersection and accompanied by the corresponding aural information, both young and old benefit. ${ }^{3}$ Elderly drivers, keen to have information confirmed, tend to use both visual and aural messages, while young drivers in many cases base their action on aural information only. ${ }^{4}$

Unlike the instructions displayed by arrows, guidance information presented in the form of a complex electronic map, with the route highlighted, turns out to be difficult to use, even more so among elderly drivers. ${ }^{5}$ Generally, the difference in performance between young and old is small for simple situations, but increases in more complex ones.

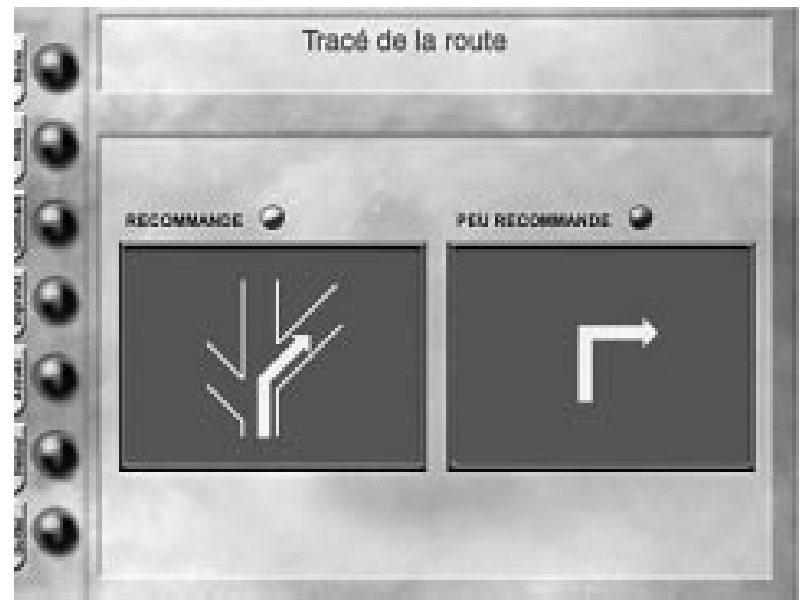

Figure 8 Example of a screen page from the CD-ROM showing a recommendation for the display of guidance information. A real life situation has shown that a schematization of the route helps the driver make decisions (version on left recommended) by comparison with just a display out of context, even with correctly adjusted contrast (right).

\section{Evaluation of driver's mental workload}

Though the real life situation is very revealing, it does not tell us about the effort involved on the part of the driver. For example, much can be learned from a comparison between the visual strategies needed to get information from the in-car screen, and from identifying which messages necessitate the longest glances - that is, which take the driver's eyes off the road the longest. For durations not considered as likely to cause an accident, being a non-critical length of time (this value is debatable; it is 2 seconds according to Zwhalen), the criteria for the efficacy of the message will depend on how these seconds are used by the driver. In other words, a message requiring a slightly longer consultation than another, but whose content will let the driver drive better-that is, one which has a better payoff for the driver, is preferable to one that is read quickly but is of little use. Mental workload evaluation has always been and still is a difficult field of research; although there is a wealth of possible investigative tools (electrophysiological parameters, double task management, subjective evaluation, etc), this "quantification" of the amount of activity is difficult to assess easily, cheaply, and satisfactorily. Subjective evaluation seemed to us to be worth using, insofar as it allows the overall situation to be assessed, by comparison with a reference situation. The NASA-TLX (Task Load indeX) created, as its name suggests, by NASA, has been widely used with this goal in mind the world over, mainly in aeronautics. The principle for calulating correction coefficients seemed to us pertinent, but of course the factors selected belonged more to piloting an aeroplane than to driving a car. The tool was therefore adapted and named the DALI (Driving Activity Load Index ${ }^{6}$ ). In association with other behavioural criteria, this method allowed us to assess the "usability" of different types of guidance and navigation systems, as well as of the mobile telephone.

\section{Ergonomic design recommendations}

The ergonomic recommendations made in the course of the various systems evaluations must take into account the needs and the functional specificities of elderly people. For example, the method of communicating information should be adaptable (e.g., volume and contrast control), as should the functions the system provides (e.g., guidance and navigation systems should offer the driver the options not only of the shortest, quickest route, but also the routes that avoid motorways, generally eschewed by elderly drivers). 
To increase the impact of this research on designers, a CD-ROM has been created to facilitate access to all the data on ergonomic criteria (see fig 8$)^{7}$

Several factors complicate the making of recommendations:

- The heterogeneity of the driving population in terms of functional ability, motivation, driving style, and experience, with much interaction among these elements. Design recommendations must meet a maximum of, if not all, the needs identified among drivers.

- Constant technological innovation-ergonomic recommendations must always evolve and adapt.

- Adaptation of the way ergonomic recommendations are formulated and accessed, so that they match the very diverse working methods of designers.

\section{CONCLUSION}

In the context of designing systems for elderly drivers, two conclusions have been reached:

(1) Simplifying a task reduces performance differences between old and young.

(2) The optimization of onboard systems (better legibility and intelligibility of the information; simplified dialogue) in relation to the abilities of elderly drivers benefits the rest of the user population.

These investigations have also shown that elderly people do not automatically reject new information and assistance technologies, ${ }^{8}$ especially when the systems are user friendly (though there might be complicated technology behind the system, as in natural language voice recognition, which does not require the user to learn the system). However, the ergonomics of these new technologies (acceptability, "usability", safety), must be studied, with particular attention to the specific needs of the elderly, in order not to marginalize them.

\section{Author's affiliation}

A Pauzié, INRETS/LESCOT, Lyon-Bron, France

\section{REFERENCES}

1 Pauzié A, Gabaude C. Effect of a dynamic central task on the visual field of view: investigation of visual and attentional abilities of elderly drivers. In: Gale AG, ed. Vision in vehicles-VI. Elsevier, 1998:325-32.

2 Pauzié A. Driving behavior and ergonomics of in-vehicle communicating systems. First Symposium on Measurement, Analysis and Modelling of Human functions. Saporo, Japan, 2001.

3 Pauzié A. Visual capacities and elderly drivers. In: Marquié JC, Paumes-CauBareille D, Volkoff S, eds. Working with age. Taylor \& Francis, 1998:205-8.

4 Pauzié A. Les conducteurs âgés face aux nouvelles technologies: conséquences pour l'ergonomie des systèmes d'aide à la conduite. In: Marquié JC, Paumes-CauBareille D, Volkoff S, eds. Travailler au fil de l'âge. Octares, 1995:377-90.

5 Pauzié A, Forzy J-F. Ergonomic evaluation of guidance and traffic information in the CARMINAT program. III Annual World Congress on Intelligent Transport Systems, Orlando, CD-ROM, 1996.

6 Pauzié A, Pachiaudi G. Subjective evaluation of the mental workload in the driving context. In: Rothengatter T, Carbonell Vaya E, eds. Traffic and transport psychology: theory and application. Pergamon, 1997:173-82.

7 Forzy JF, Nathan F, Pauzié A. Développement d'une base interactive de critères ergonomiques pour la conception. Ergonomie et Sécurité des systèmes communicants dans le véhicule. Les collections de l'INRETS actes de la Journée Spécialisée INRETS, 2001:113-17.

8 Pauzié A. Usability of transport web sites by elderly travellers. Universal Access in Human-Computer Interaction Conference, New Orleans, USA, 5-10 August 2001 